\title{
وظيفة الحاجب في عصر صدر الإسلام
}

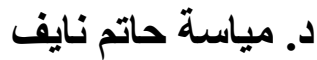

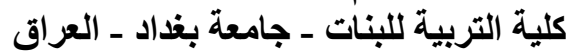 \\ البريد الاكتروني: mayasa.hatim@coeduw.uobaghdad.edu.iq
}

الملخص

الحجابة ركن مهم من أركان النظام الإداري للاولة العربية الإسلامية نالت اهتمام الفقهاء حتى وضعوا لها الثروط فيمن ينو لاها والواجبات عليه، ظهرت في عصر صدر الإسلام و أكدت المصادر التاريخية وجودها في عصر النبي (صلى الله عليه وسلم )ولكن لم تكن لها أنظمة ومر اسيم معقدة إذ لم يتعد عمل الحاجب طلب الأذن من النبي(صلى الله عليه وسلم ) لمن يريد مقابلته في الأوقات التي يفضل فيها النبي (صلى الله عليه وسلم ) أن يخلو بنفسه في المسد أو في بيته أما الأوقات الأخرى فلم يلزمه (صلى الله عليه وسلم ) وجود الحاجب أو لهاب اله

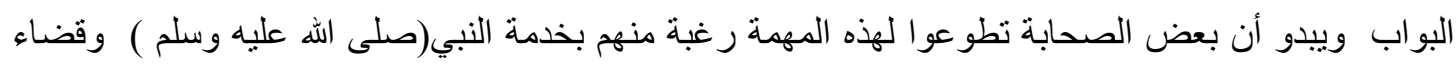

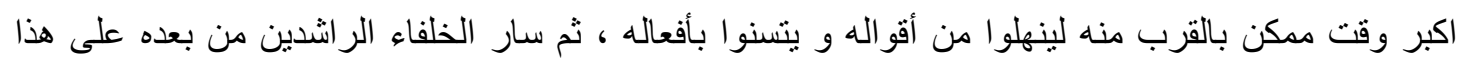
السياق ولكن عمله أيضا لم يتعد تنظيم عملية الدخول على الخليفة وان وضع لعملية الدخول معايير أهمها السابقة في الإسلام ثم حظيت هذه الوظيفة باهتمام الأمويين حتى جعلوها حكر ا على المو الين و المقربين لهم الأمر الذي الذي أدى إلى الاعتقاد إلى أنها من الوظائف المستحدثة في العصر الأموي ،و ارتفعت مكانة من يتولى هذه الوظيفة في الخلافة العباسية حتى تدخل صاحبها في كثير من أمور الحكم (1). الكلمات المفتاحية: وظيفة الحاجب، عصر صدر الإسلام. 


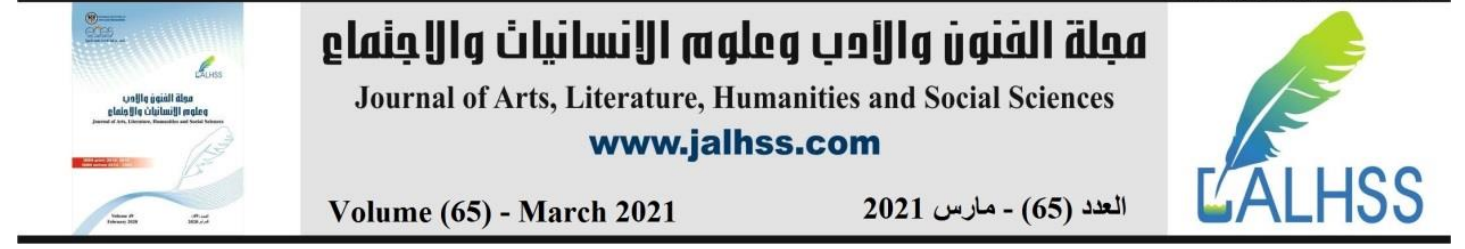

\title{
The Eyebrow Function in the Era of Early Islam
}

\author{
Dr. Maysa Hatem Nayef \\ College of Education for Girls - University of Baghdad - Iraq \\ Email: mayasa.hatim@coeduw.uobaghdad.edu.iq
}

\begin{abstract}
The hijab is an important pillar of the administrative system of the Arab Islamic state that gained the attention of the jurists until they set the conditions for it in the person who handles it and the duties on him. The work of the pilgrim Asking permission from the Prophet (peace and blessings be upon him) for those who want to meet him at times when the Prophet (peace and blessings be upon him) prefers to be alone in the mosque or in his home. It seems that some of the Companions volunteered for this task in order to serve the Prophet (may God's prayers and peace be upon him) and spend as much time as possible near him in order to draw from his words and make his deeds easier. Then the rightly-guided caliphs followed him in this context, but his work also did not go beyond organizing the process of entering the caliph. The entry process set standards, the most important of which are the previous ones in Islam, and then this job gained the attention of the Umayyads until they made it the preserve of the loyal and those close to them, which led to the belief that it was one of the jobs created in the Umayyad era, and the status of those who assumed this job increased In the Abbasid caliphate, until its owner interfered in many matters of governance.
\end{abstract}

Keywords: the function of the eyebrow, the era of early Islam. 


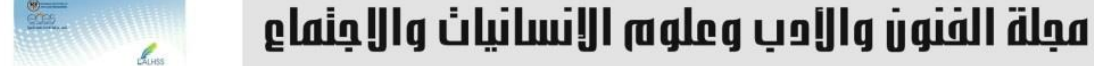 \\ Journal of Arts, Literature, Humanities and Social Sciences www.jalhss.com

\section{:تمهبد :}

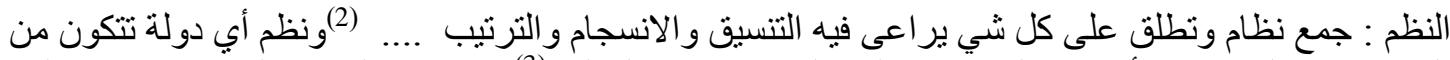

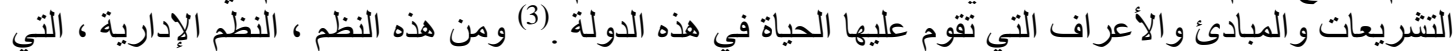

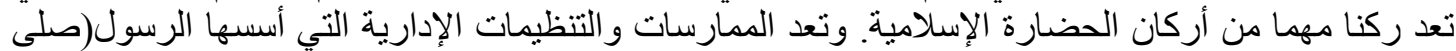

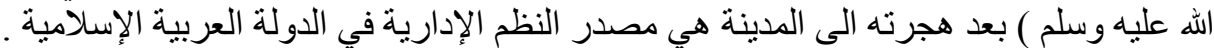

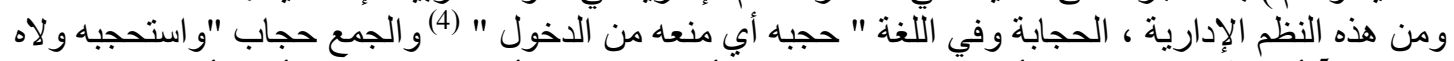

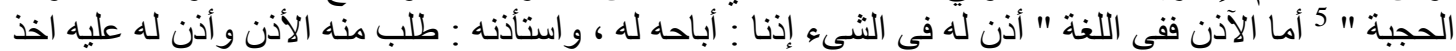

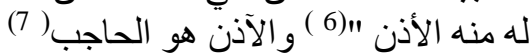

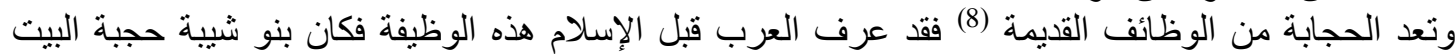

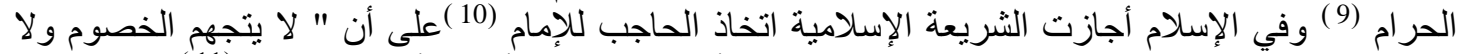

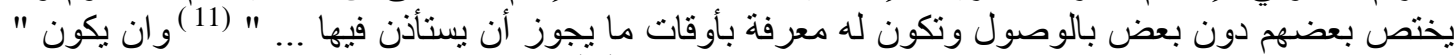

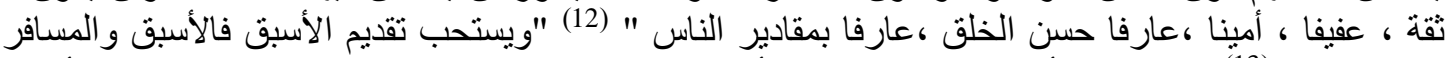

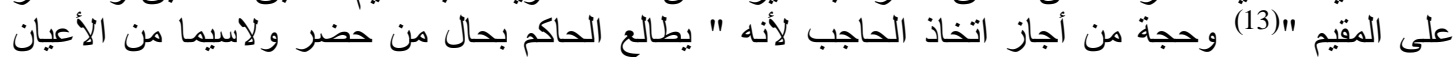

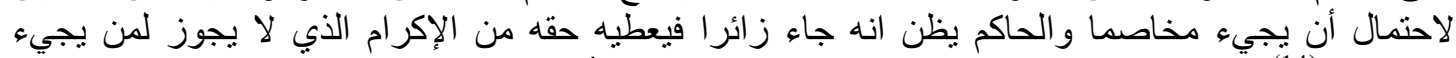

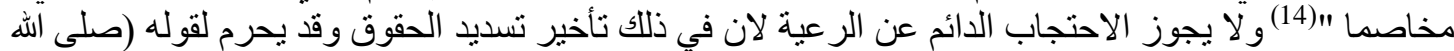

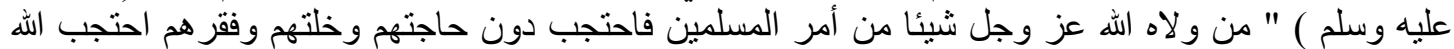
عنه دون حاجته وخلته "(15) عن لاه

\section{وظيفة الحاجب في عصر صدر الإسلام :}

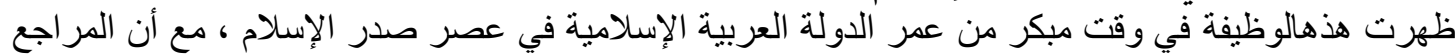

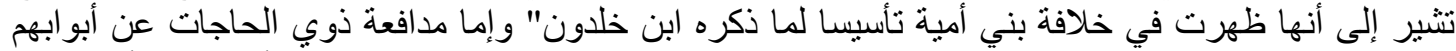

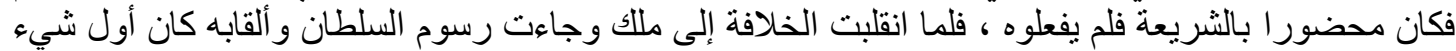

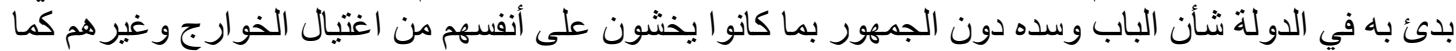

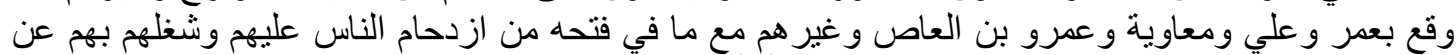

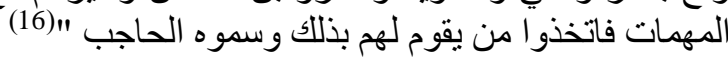

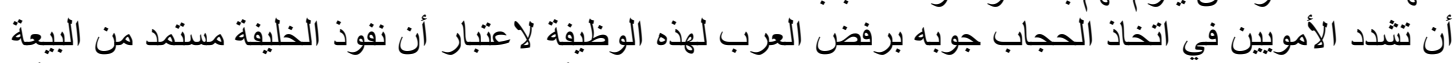

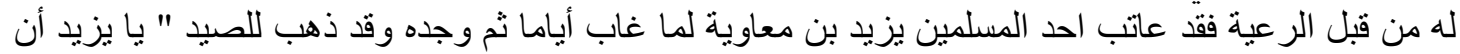

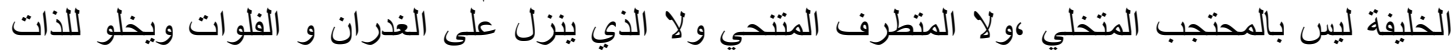

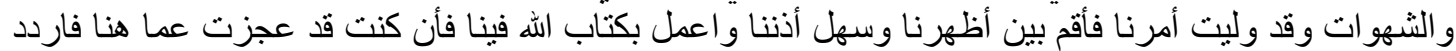

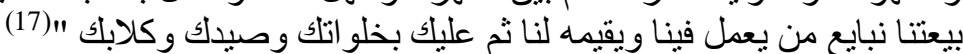

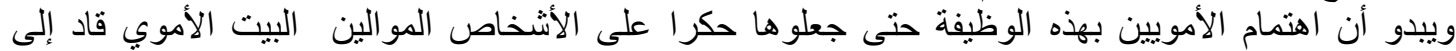

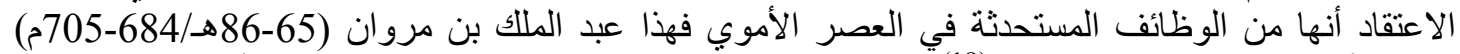

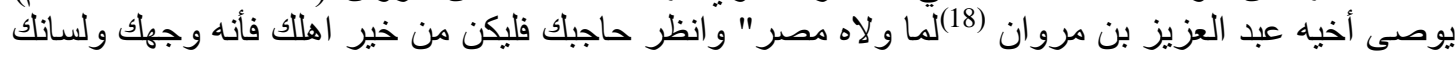

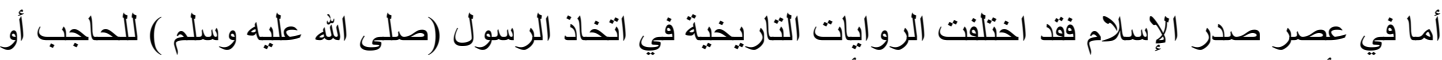

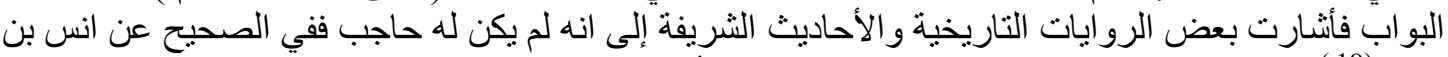

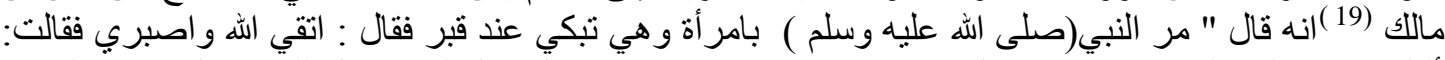

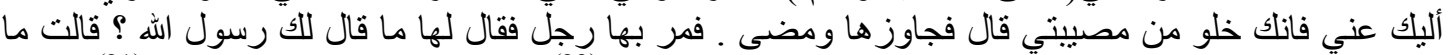

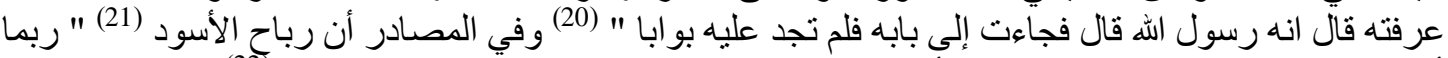

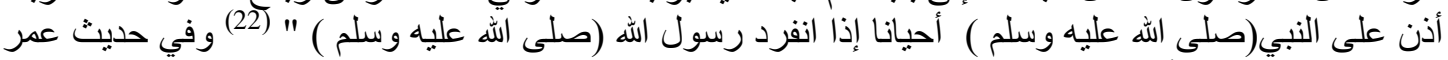

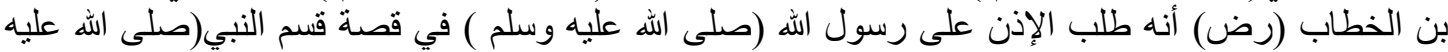

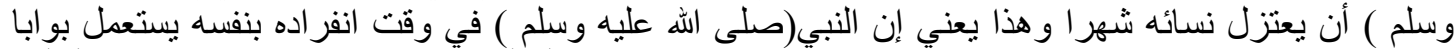

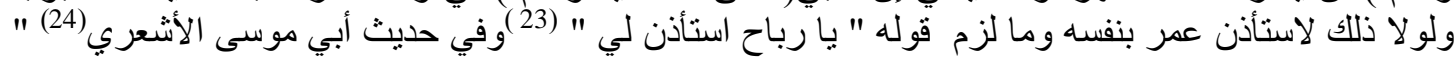




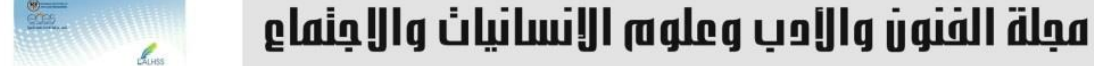 \\ Journal of Arts, Literature, Humanities and Social Sciences www.jalhss.com

خرج النبي (صلى الله عليه وسلم ) إلى حائط من حو ائط المدينة لحاجته وخرجت في أثره فلما دخل الحائط

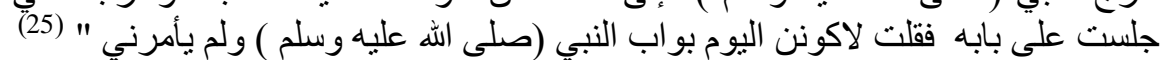

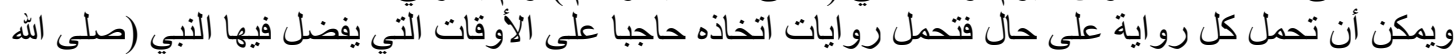

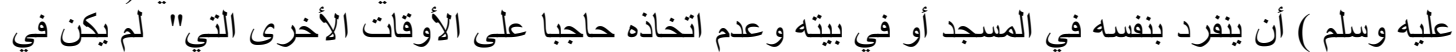
شغل من أهله و لا انفر اد من أمره " و على كل حال لم تكن للحجابة في عهد الرسول (صلى الله عليه وسلم ) أنظمة ومر اسيم معقدة بل كان الصحابة يتطو عون في الأذن على رسول الله (صلى الله عليه وسلم ) في الأوقات التي كان يفضل فيها أن ينفرد في المسجد

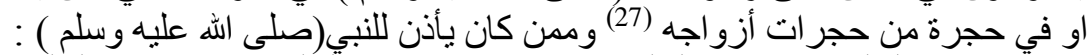

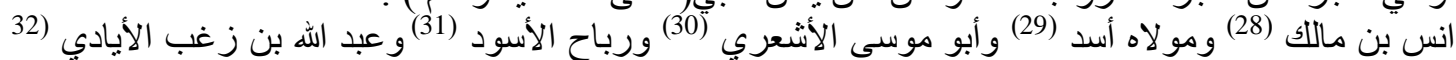

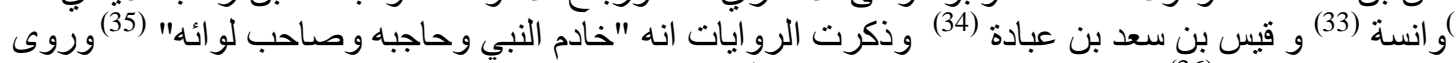

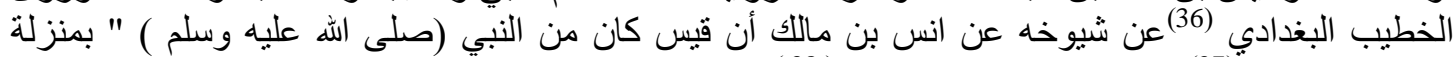

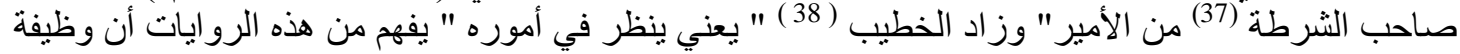

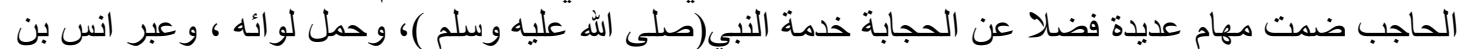

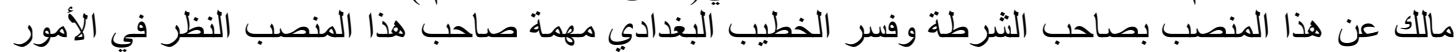

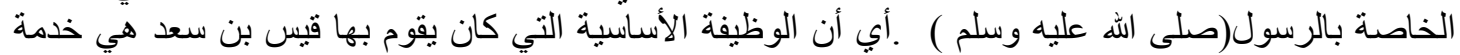

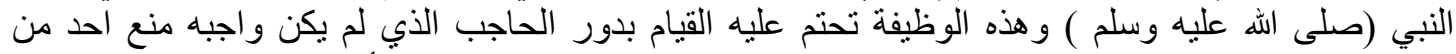

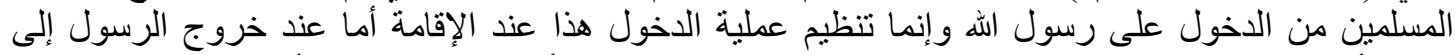
غزوة أو معركة فيكون حمل لواء رسول الله وتقدمه بين يديه من أهم واجباته ويبدو أن قيس بن سعد تمتع بشخصية قوية وصارمة جعلت المهاجرين من المسلمين يكلمون الرسول(صلى الله عليه وسلم ) لكي" يصرفه فئه

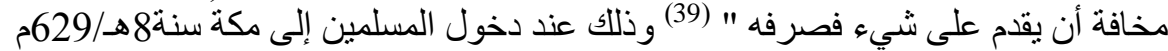
وفي عهد الخليفة أبو بكر الصديق (رض) (11-13هـ/632-634م) كانت الإدارة في في الدولة فئلة العربية الإسلامية

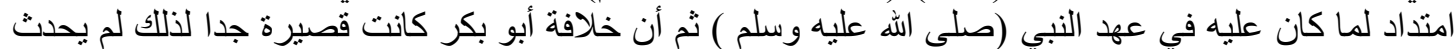
تطوركبير في عهده فاختقت المعلومات عن هذه الوظيفة باستثناء ما ذكرته المصادر أن سديف أو شديد حاجب أبو بكر (40) ومع أن الخليفة عمر بن الخطاب (رض) (13-23هـ-634-643م)شدد في وصاياه إلى عماله على ضرورة

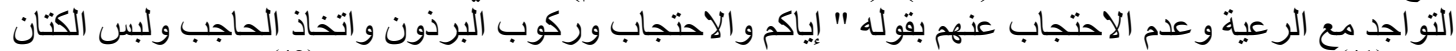

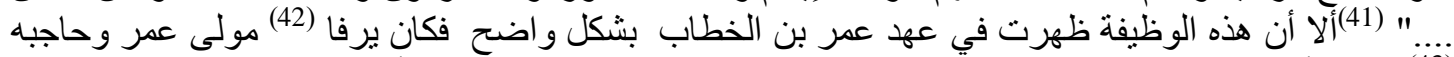

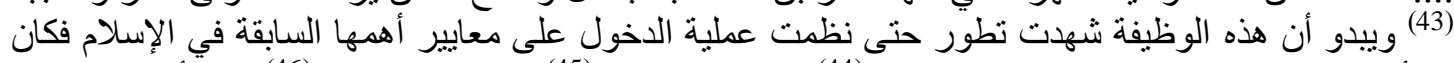

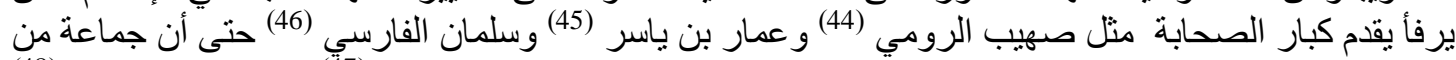

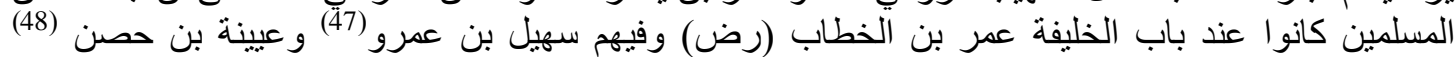

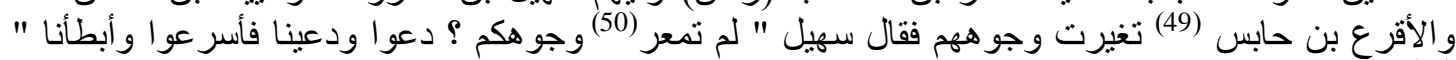

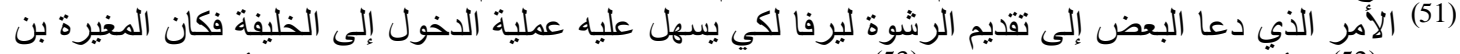

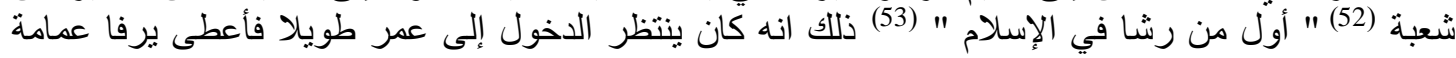

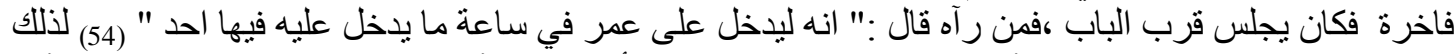

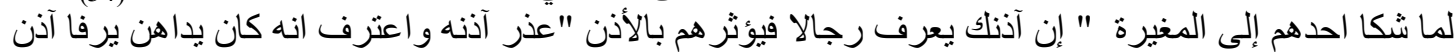

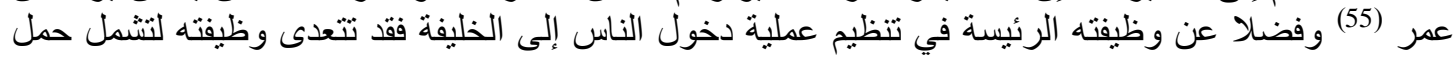

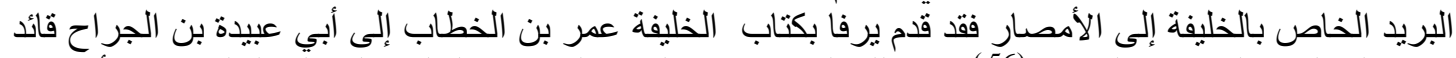

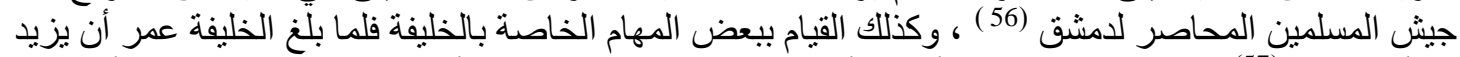

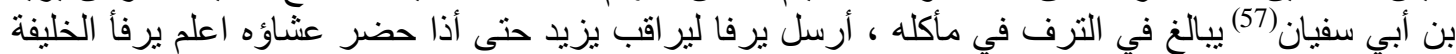

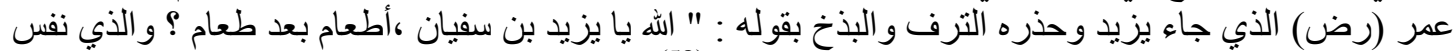

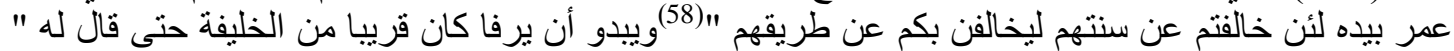

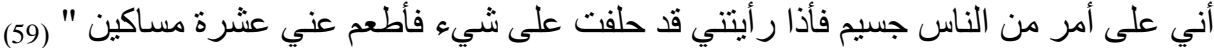

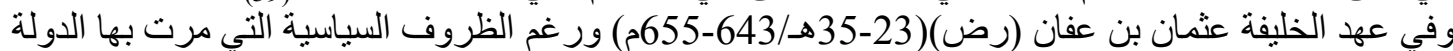

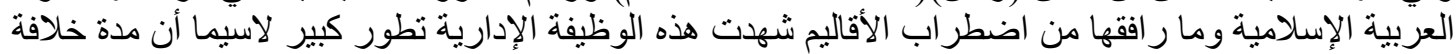




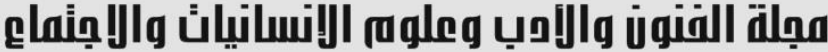

\author{
Journal of Arts, Literature, Humanities and Social Sciences
} www.jalhss.com

Volume (65) - March 2021

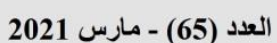

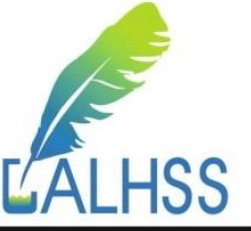

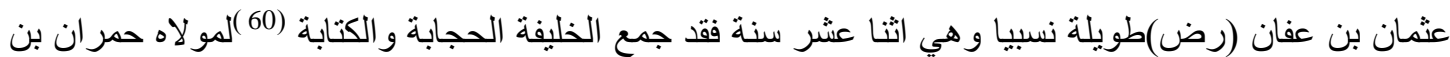

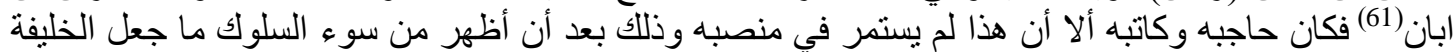

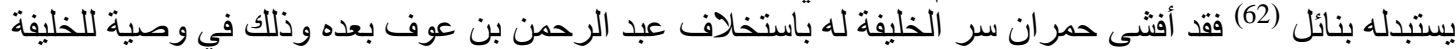

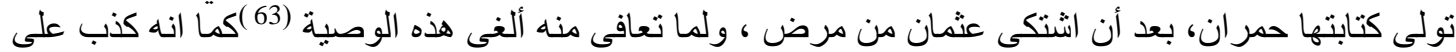

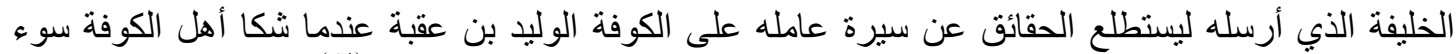

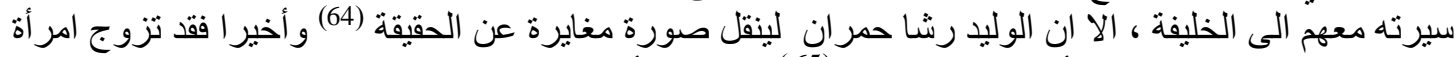

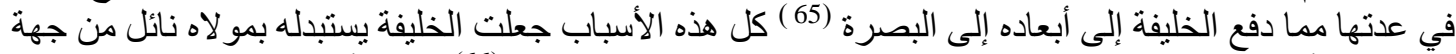

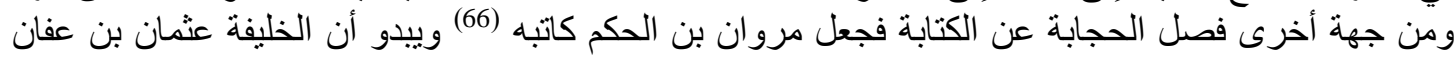

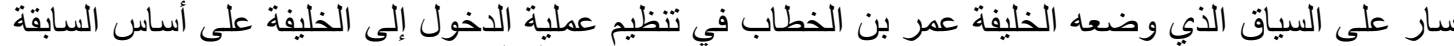

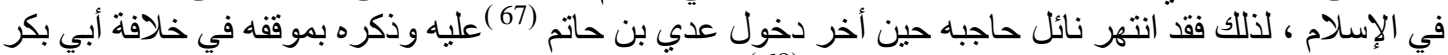

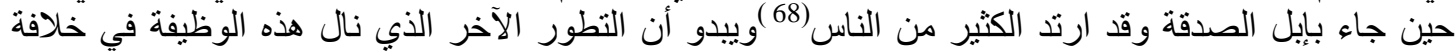

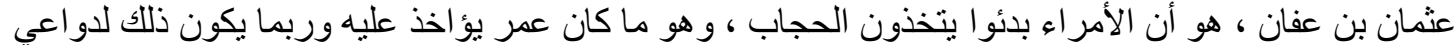

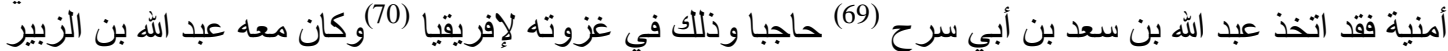

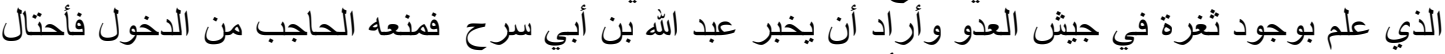

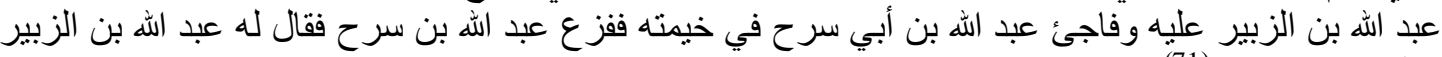

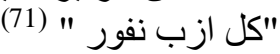

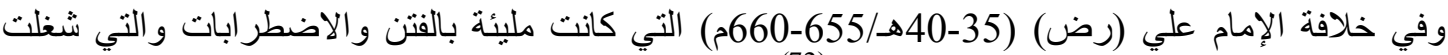

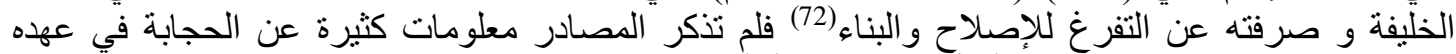
باستثناء أن من حجب له مو لاه بشر (73 لثم مو لاه ولاه قنبر (74)

الهوامش

1ــابن الطقطقي ، محمد بن علي بن طباطبا (709 هـ /1308م ) ، الفخري في الآداب السلطانية تحقيق: عبد القادر محمد مايو

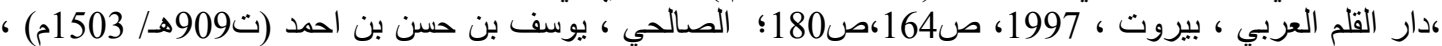
إيضاح طرق الاستقامة في بيان أحكام الولاية والإمامة ، تحقيق: مجموعة من المحققين بإنشراف نور الدين طالب ، دار بار

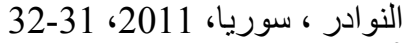

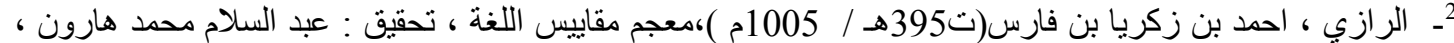

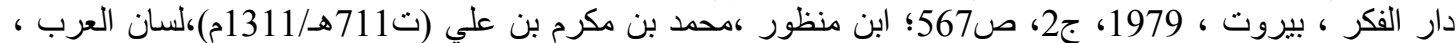

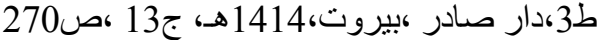

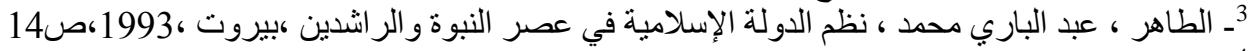

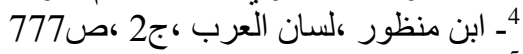

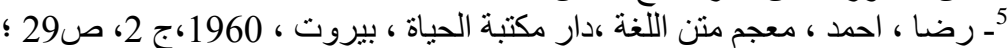

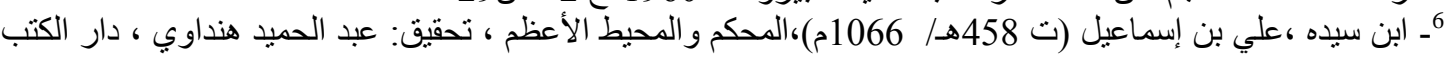

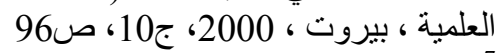

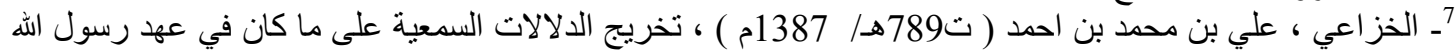

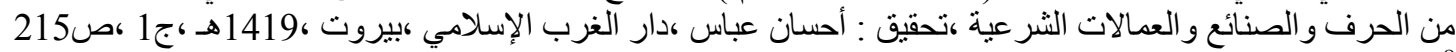

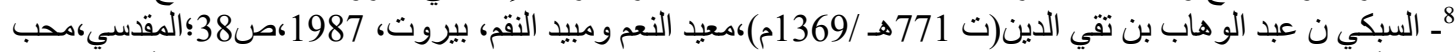

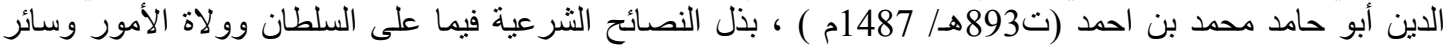

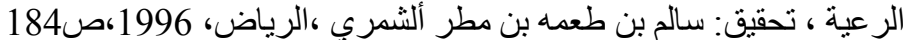

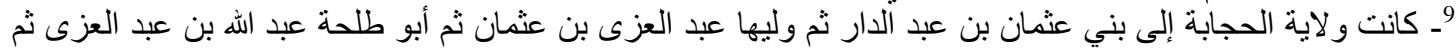

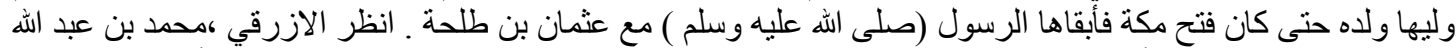

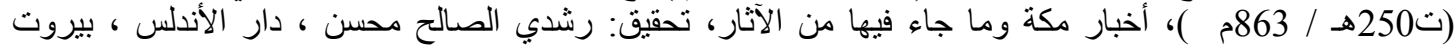

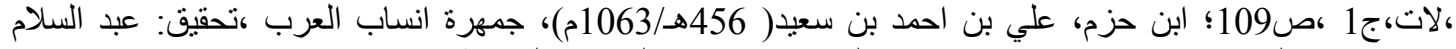

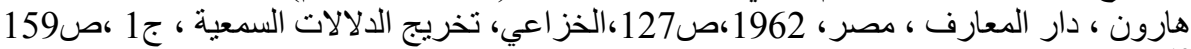

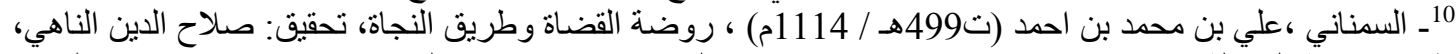

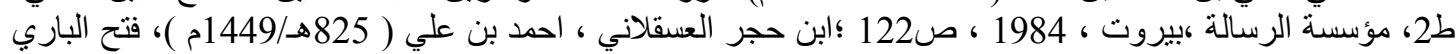




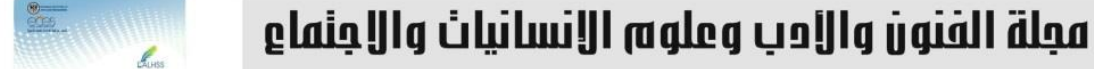 \\ Journal of Arts, Literature, Humanities and Social Sciences www.jalhss.com \\ Volume (65) - March 2021

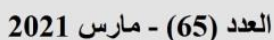

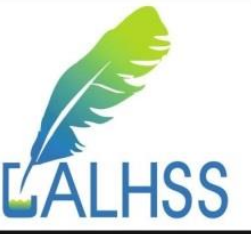

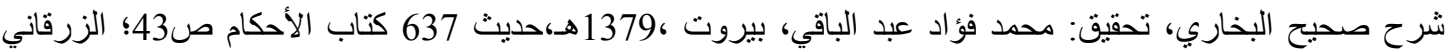

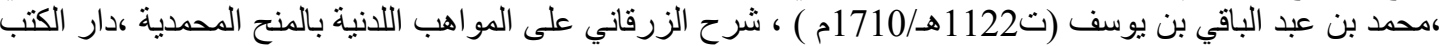

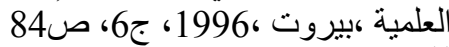

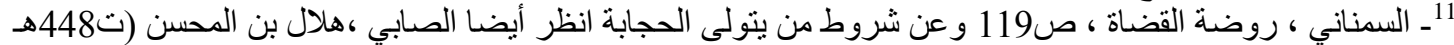

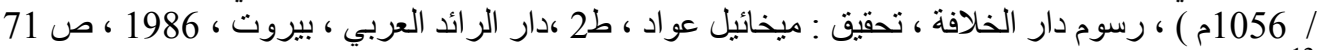

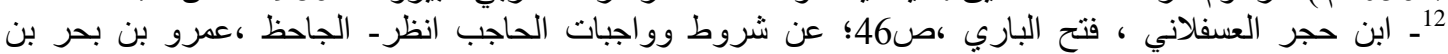

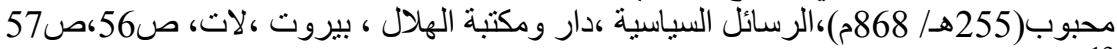

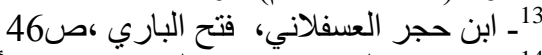

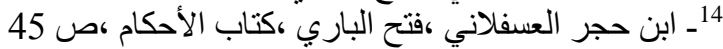
15 أبو داود ، سليمان بن الأشعث السجستاني(ت 275هـ/ 888م)، السنن ، تحقيق: محمود خليل ، دار الفكر ، بيروت،

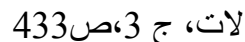
16 ـعبد الرحمن بن محمد (ت833هـهـ /1406م ) ) ، المقدمة ، دار القلم ، بيروت ، 1984، ص296

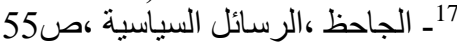
18 ـعبد العزيز بن مروان بن الحكم تولى مصر لأبيه وأخيه عبد الملك وعمر فيها الدور و المساجد وزرع فيها الكرم

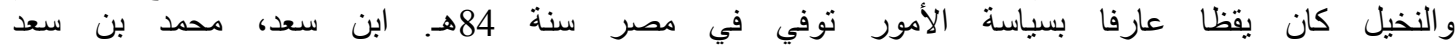

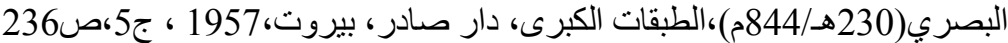

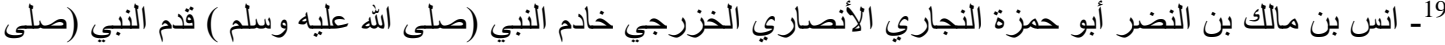

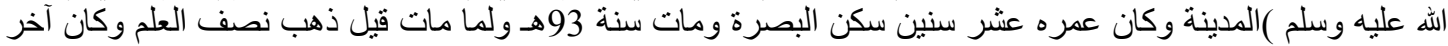

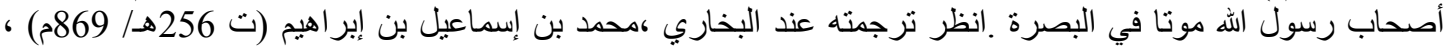

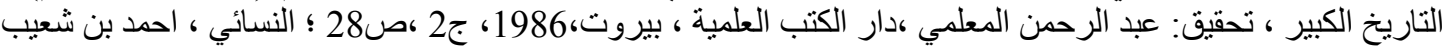

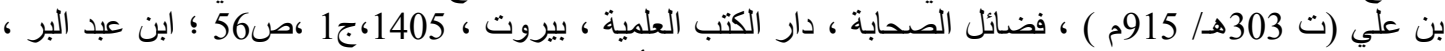

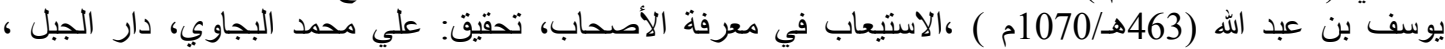

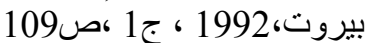

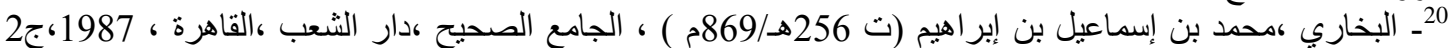

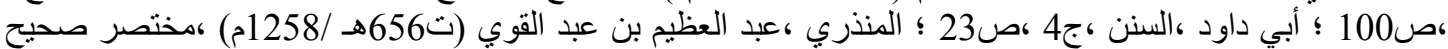

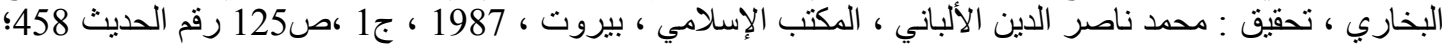

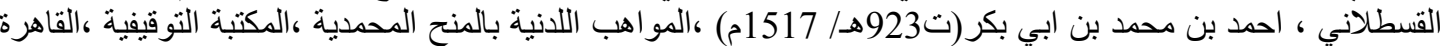

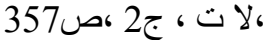

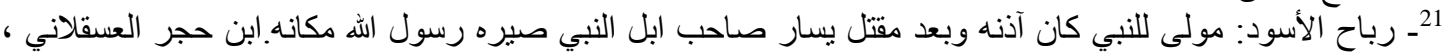

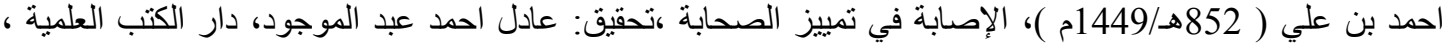

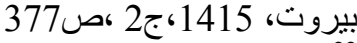

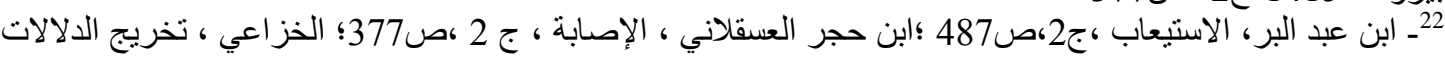

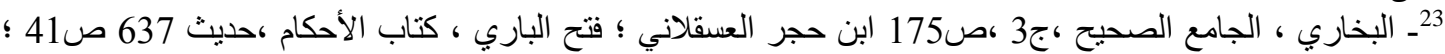

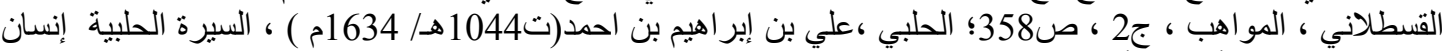

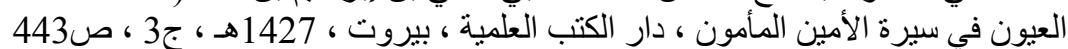

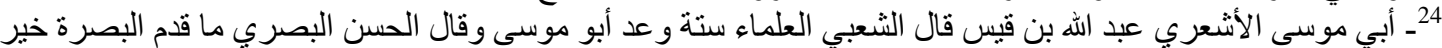

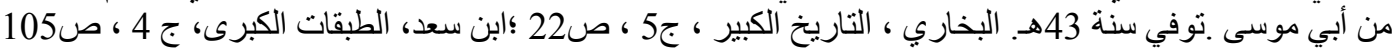

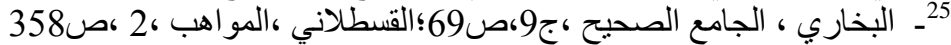

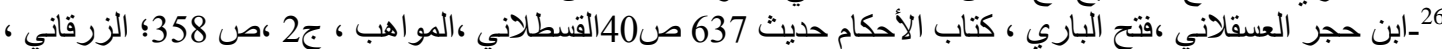

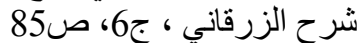

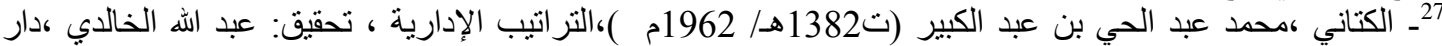
الأرقم ،بيروت، لاتص927؛ كرمي ، احمد عجاح ،الإدارة في عصر الرسول (صلى الله عليه وسلم )، دار السلام ، القاهرة

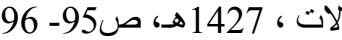

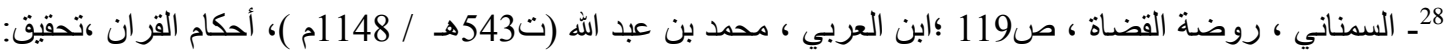

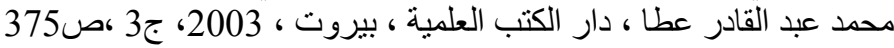




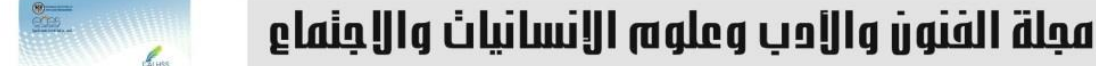 \\ Journal of Arts, Literature, Humanities and Social Sciences www.jalhss.com \\ Volume (65) - March 2021

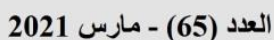

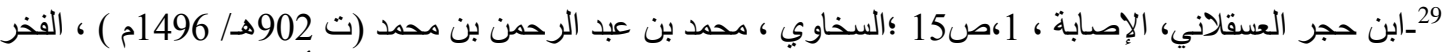

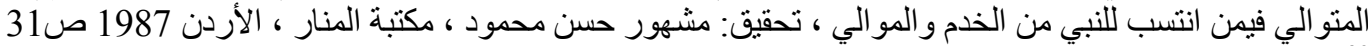

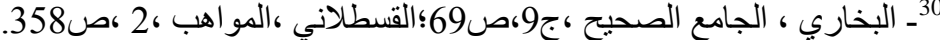

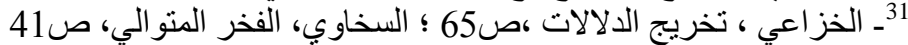

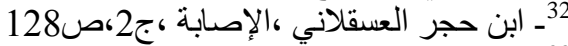

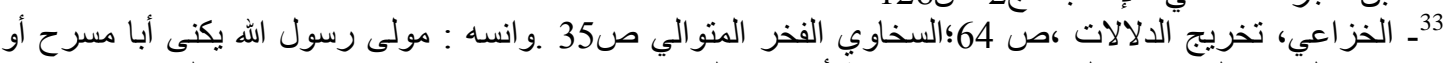

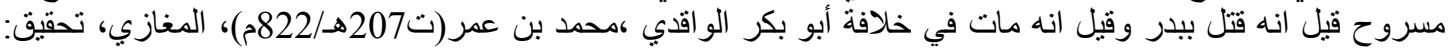

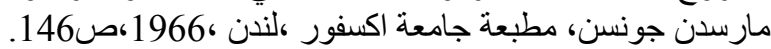

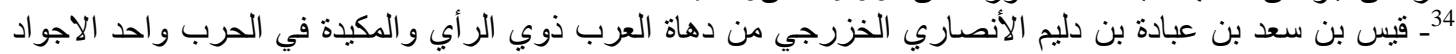

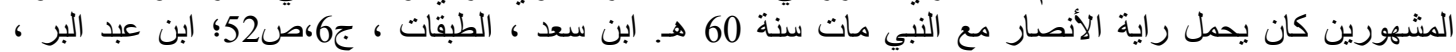

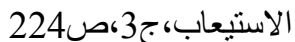
35ـ ابن عساكر ، علي بن الحسن بن هبة اله (571هـ1175م)، تاريخ دمشق الكبير ، تحقيق: علي عاشور الجنوبي ،دار

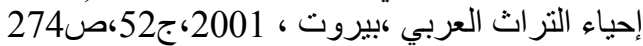
36ـ الخطيب البغدادي، احمد بن علي بن ثابت(ت463هــ/ 1070)،تاريخ بغداد ، تحقيق: بشار عو اد معروف، دار الغرب

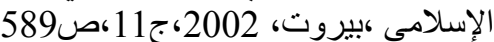

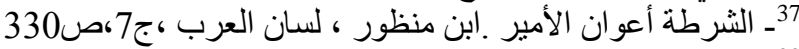

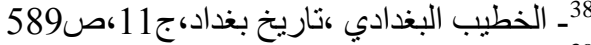

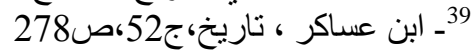

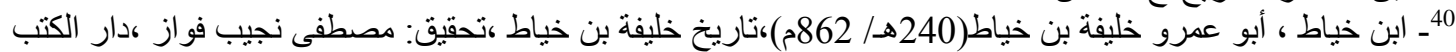

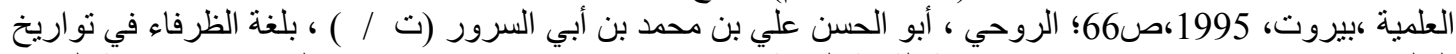

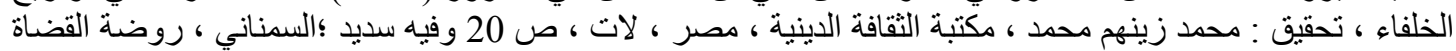

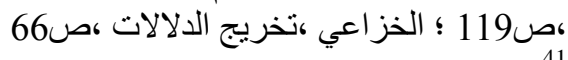

42 ــ يرفأ : مولى عمر بن الخطاب (رض) سمع عمر وعثمان و طلحة و الزبير روى عنه أبو اسحاق السبيعي ـ انظر

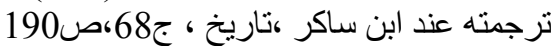

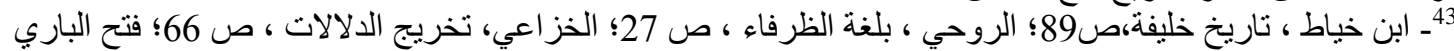

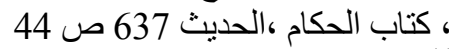

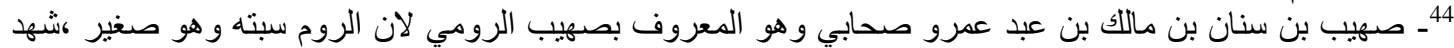

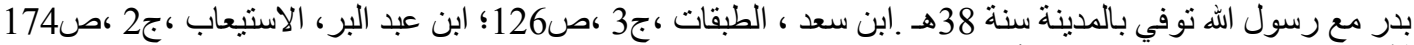

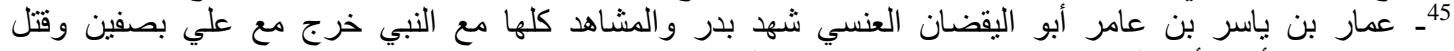

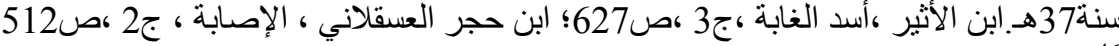

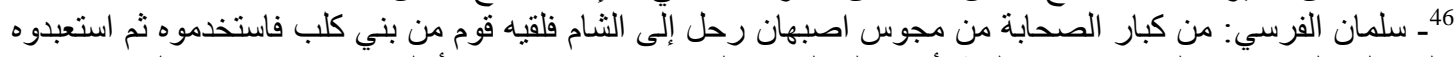

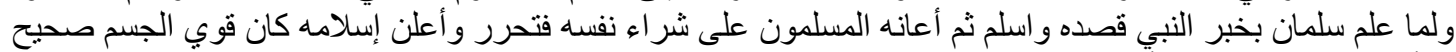

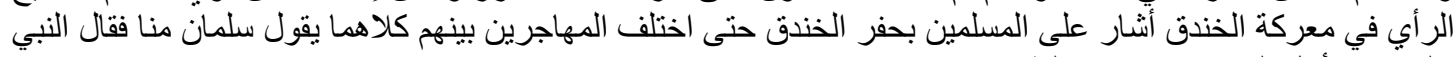

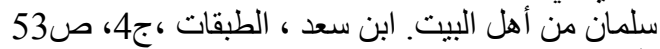

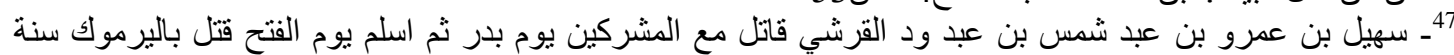

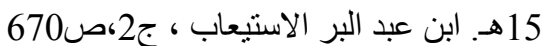

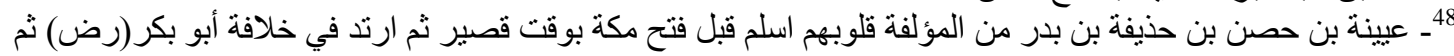

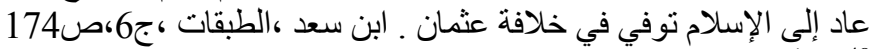

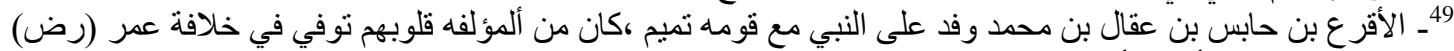

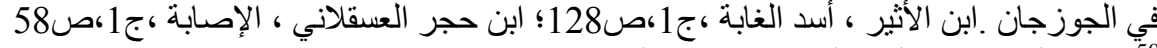

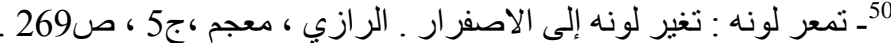

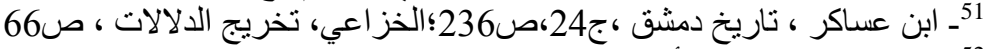

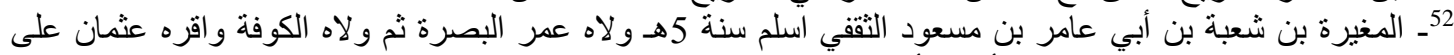

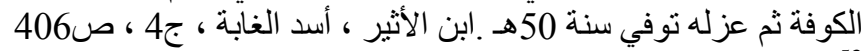

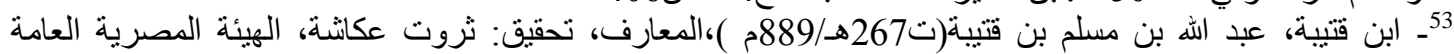

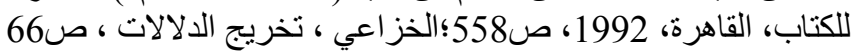




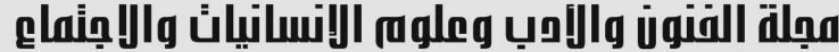

Journal of Arts, Literature, Humanities and Social Sciences www.jalhss.com

Volume (65) - March 2021

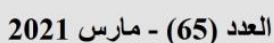

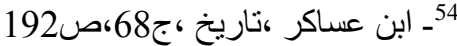

55_البسوي، يعقوب بن سفيان(277هــ/890م)، المعرفة والتاريخ ،تحقيق: أكرم ضياء العمري ،ط2،مؤسسة الرسالة، بيروت

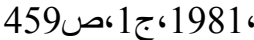

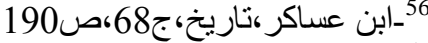

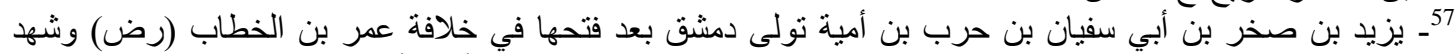

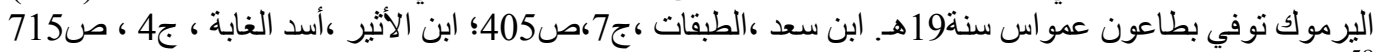

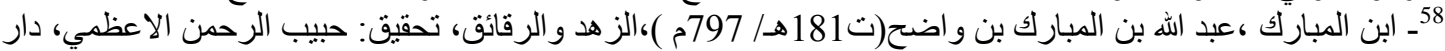

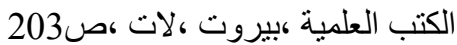

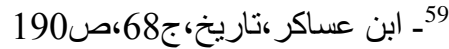

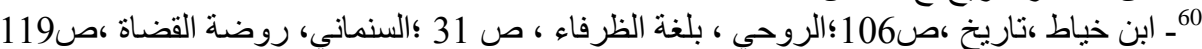

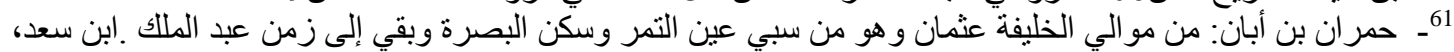

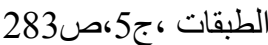

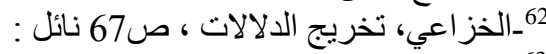

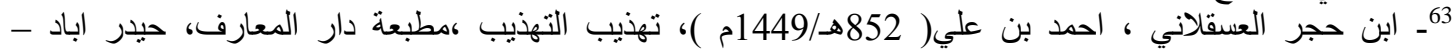

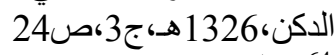

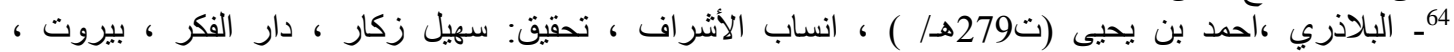

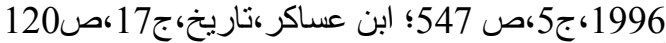

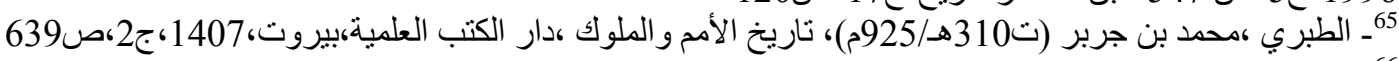

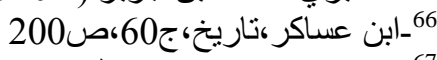

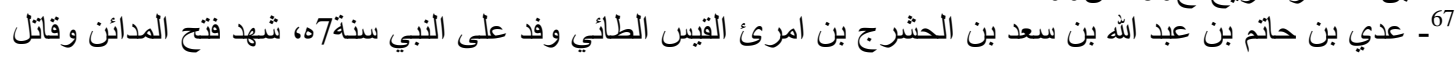

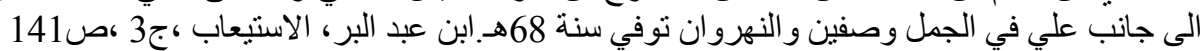

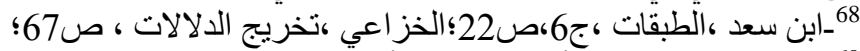

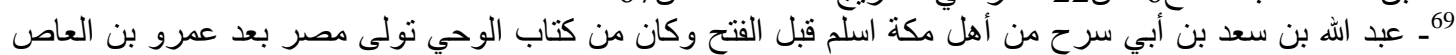

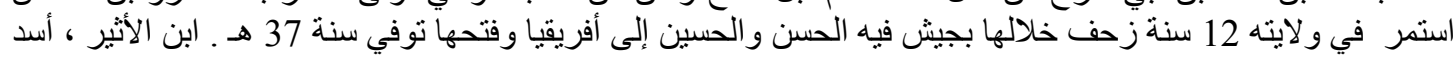

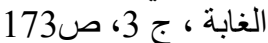

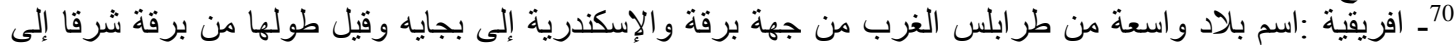

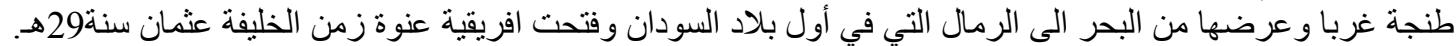

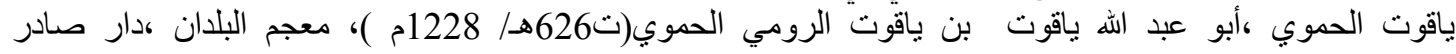

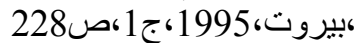

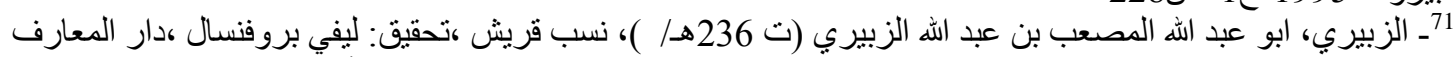

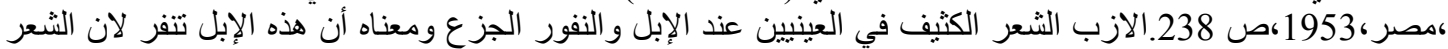

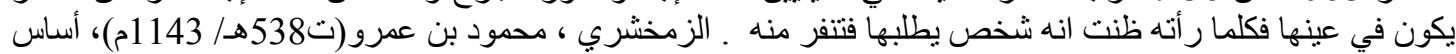

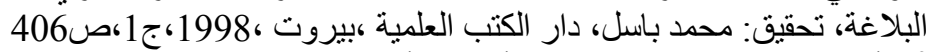

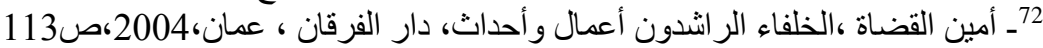

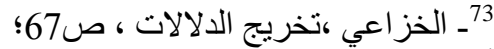

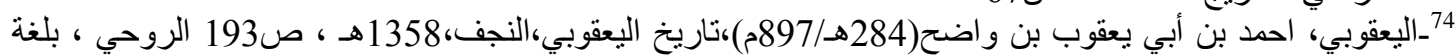

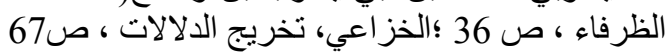

1- المصادر الأثير ،علي بن محمد بن محمد( ت630هـ/ 1232م )، أسد الغابة في معرفة الصحابة ،تحقيق: علي بـابي

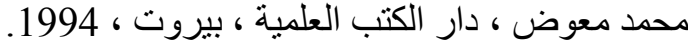

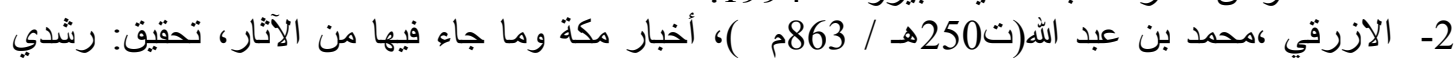

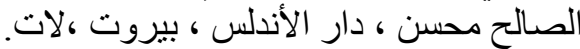
3- البخاري ، محمد بن إسماعيل بن إبرانيم الأليم (ت 256هـ/ 869م) ، التاريخ الكبير ، تحقيق: عبد الرحمن

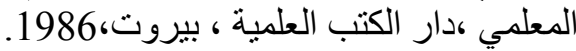
4- الجامع الصحيح ،دار الثعب ،القاهرة ، 1987. 


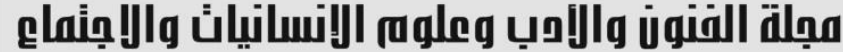

Journal of Arts, Literature, Humanities and Social Sciences www.jalhss.com

Volume (65) - March 2021

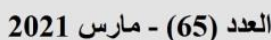

5- البسوي، يعقوب بن سفيان(277هـ/890م)، المعرفة والتاريخ ،تحقيق: أكرم ضياء العمري ،ط2،مؤسسة

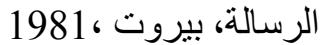

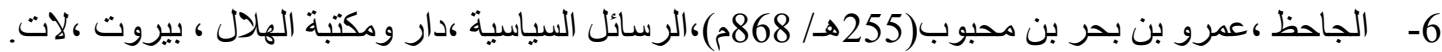

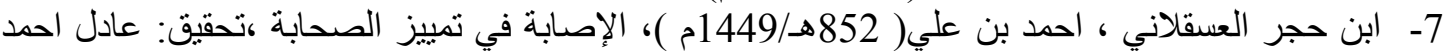

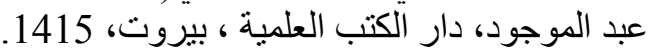
8- - ابن حجر العسقلاني ، احمد بن علي( 825هـ/1449م )، تهذيب التهذيب ،مطبعة دار المعارف، حيدر اباد

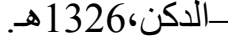

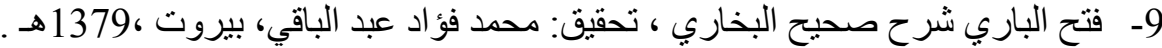
10- ابن حزم، علي بن احمد بن سعيد (456هـ/1063م)، جمهرة النساب العرب ،تحقيق: عبد السلام هارون ،

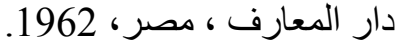

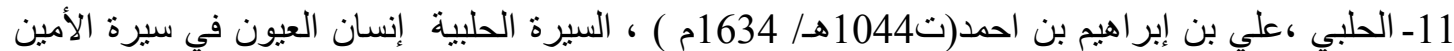

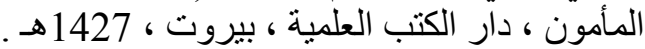

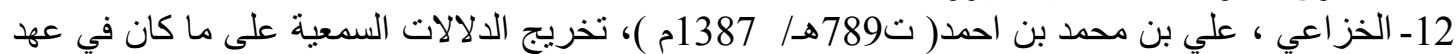

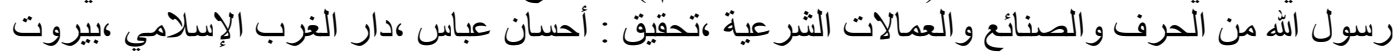
1419، 13- الخطيب البغدادي ،احمد بن علي بن ثابت(تأ463هـ/ 1070م )،تاريخ بغداد، تحقيق: بشار عو اد معروف،

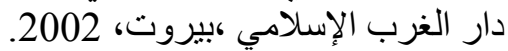

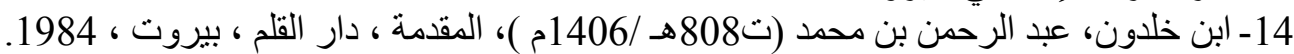

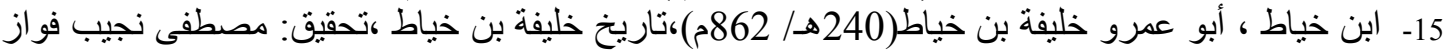

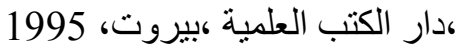
16- أبو داود ، سليمان بن الأشعث السجستاني(ت 275هـ/ 888م)، السنن ، تحقيق: محمود خليل ، دار الفكر ،

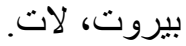
17ـ الرازي ، احمد بن زكريا بن فارس(ت395هـ / 1005م )،معجم مقاييس اللغة ، تحقيق : عبد السلام محمد

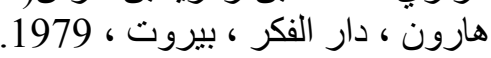

18- الروحي ، أبو الحسن علي بن محمد بن أبي السرور (ت / ) ) ، بلغة الظرفاء في تواريخ الخلفاء ، تحقيق :

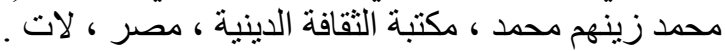
19- الزبيري ،أبو عبد الله المصعب بن عبد الله الزبيري (ت 236هــ/ )، نسب قريش ،تحقيق: ليفي بروفنسال

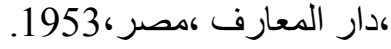

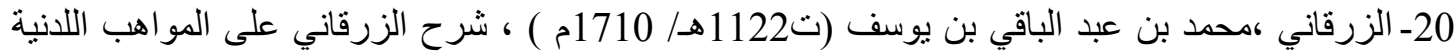

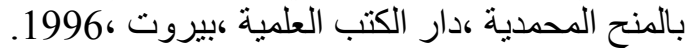
21- ـ الزمخشري ، محمود بن عمرو(ت538هـ/ 1143م)، أساس البلاغة، تحقيق: محمد باسل، دار الكتب

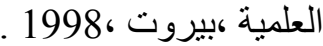

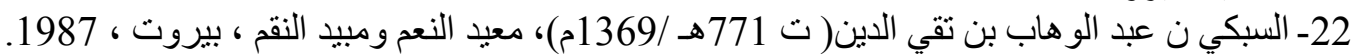

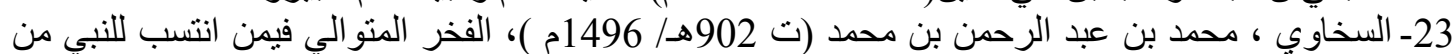

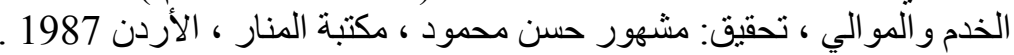

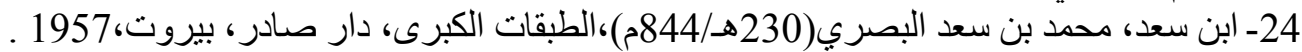

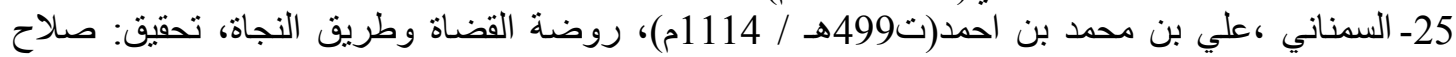

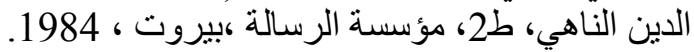
26- ابن سيده ،علي بن إسماعيل (ت 458هـ/ 1066م)، المحكم والمحيط الأعظم ، تحقيق: عبد الحميد هنداوي

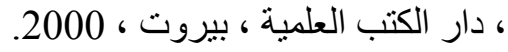

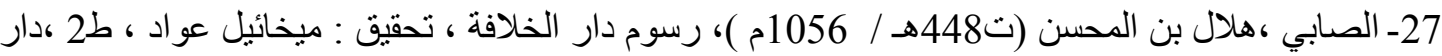

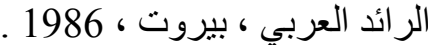




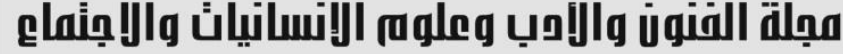

Journal of Arts, Literature, Humanities and Social Sciences www.jalhss.com

28- الصالحي ، يوسف بن حسن بن احمد(توب09هـ/ 1503م)، إيضاح طرق الاستقامة في بيان أحكام الولاية

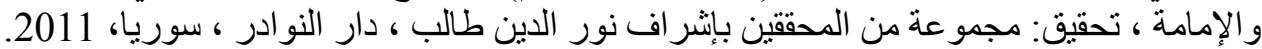

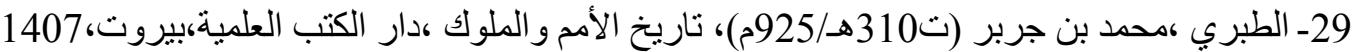

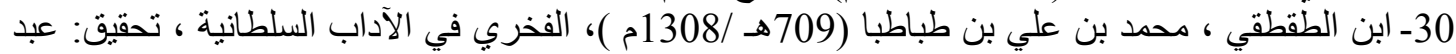

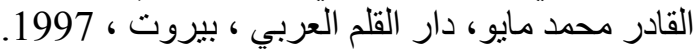
31- ابن عبد البر ، يوسف بن عبد البد الله (463هـ/1070م )، 1993، الاستيعاب في معرفة الأصحاب، تحقيق: علي محمد

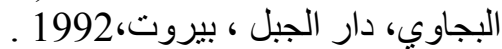
32- ابن العربي ، محمد بن عبد الله (ت543هـ الكئ / 1148م )، أحكام القران ،تحقيق: محمد عبد القادر عطا ، دار

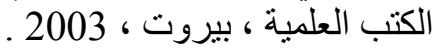
33- ابن عساكر ، علي بن الحسن بن هبة الله (571هــ1175م)، تاريخ دمشق الكبير ، تحقيق: علي عاثشور

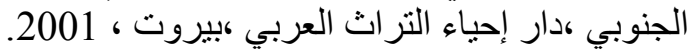
34- ابن قتيبة، عبد الله بن مسلم بن فتيبة(تراكية 276هـ/ 889م )، المعارف، تحقيق: ثروت عكانشة، الهيئة المصرية

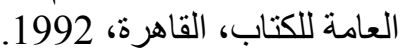

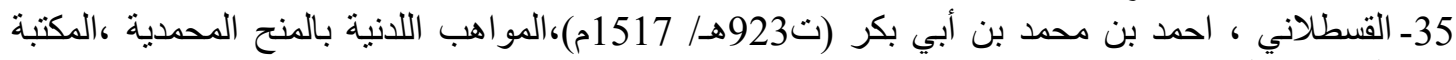

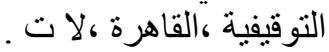

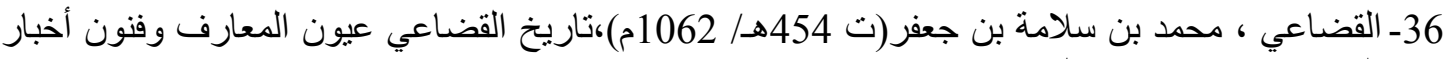

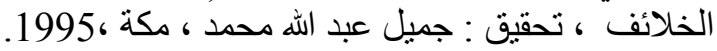

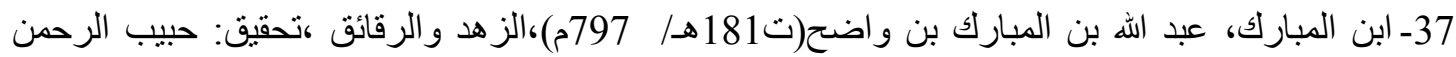

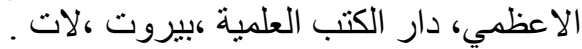

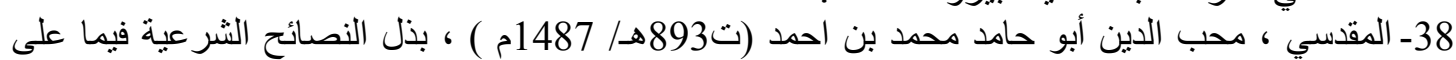

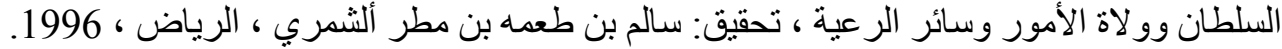

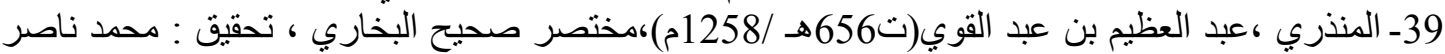

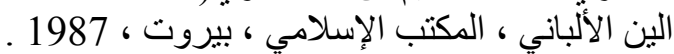
40- ابن منظور ،محمد بن مكرم بن علي (ت

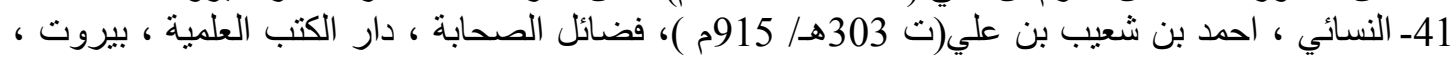
1405

42- الو اقدي ،محمد بن عمر(ت207هـ/822ه)، المغازي ،تحقيق: مارسدن جونسن ،مطبعة جامعة اكسفورد

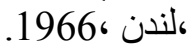
43- ياقوت الحموي ،أبو عبد الله ياقوت بن باقوت الرومي الحموي(ت626هـ/ 1228م )، معجم البلدان ،دار

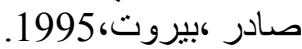
44- اليعقوبي، احمد بن أبي يعقوب بن و اضح(284هـ/897م)،تاريخ اليعقوبي،النجف،1358 هـ.

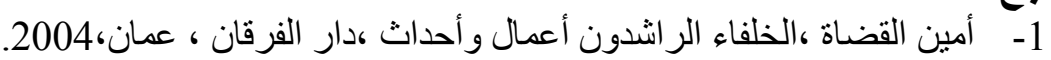

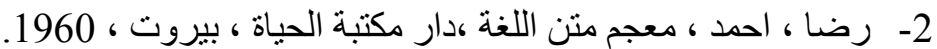

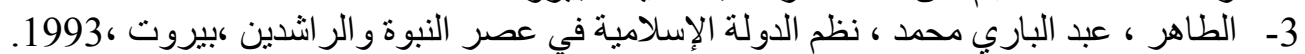

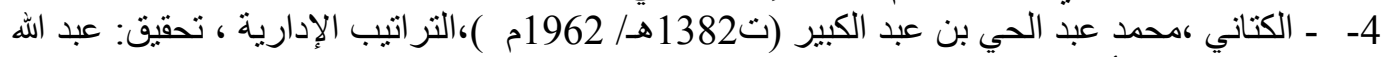

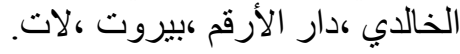
5- كرمي ، احمد عجاح ،الإدارة في عصر ،لآت الرسول (صلى الله عليه وسلم )، دار السلام ، القاهرة لات ، 


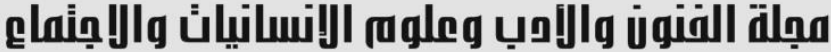

Journal of Arts, Literature, Humanities and Social Sciences www.jalhss.com

Volume (65) - March 2021

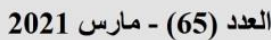

\section{References}

1- Ibn al-Atheer, Ali bin Mohammed bin Mohammed (630 AH / 1232 AD), Lion of the forest in the knowledge of the Companions, investigation: Ali Mohamed Moawad, Dar al-Kuttab al-Sulti, Beirut, 1994.

2- Azraqi, Muhammad bin Abdullah (250 H / 863 AD), the news of Mecca and its implications, the investigation: RushdiSalehMuhsin, Dar al-Andalus, Beirut, Lat.

3- Bukhari, Muhammad bin Ismail bin Ibrahim (256 H / 869 AD), the great history, the investigation: Abdul Rahman al-Maalami, Dar al-Kuttab al-Ulmiyya, Beirut, 1986.

The right mosque, Dar al-Shaab, Cairo, 1987.4-

5- Al-Basawi, YacoubibnSufyan (277 AH / 890 CE), Knowledge and History, by: Akram Zia Al-Amri, II, Al-Resala Foundation, Beirut, 1981

6- Al-Jahiz, Amr bin Bahr bin Mahboub (255 AH / 868 AD), Political Messages, Dar Al-Hilal Library, Beirut, Lat.

7- IbnHajar al - Askalani, Ahmed bin Ali (825 AH / 1449 AD), the injury in the distinction of the companions, the investigation: Adel Ahmed Abdul - Muqeem, Dar al - Kuttab al - 'Alami, Beirut, 1415.

8- IbnHajar al-Askalani, Ahmed bin Ali (825 AH / 1449 AD), the refinement of the discipline, Dar al-Ma'arif Press, Hyderabad -Delkin, 1326 e.

9- Fath al-Bari SharhSahihBukhari, investigation: Mohamed Fouad Abdel-Baqi, Beirut, 1379 e.

10- IbnHazm, Ali bin Ahmed bin Said (456 AH / 1063 AD), the mass of the Arabs, the investigation: Abdel Salam Harun, Dar Maaref, Egypt, 1962.

11- Halabi, Ali bin Ibrahim bin Ahmed (T 1044 AH / 1634 AD), biography AlHalabiyya human eye in the biography of Secretary of the safe, scientific books House, Beirut, 1427.

12- Khuzaie, Ali bin Mohammed bin Ahmed (d 789 e / $1387 \mathrm{~m}$ ), the graduation of audio dramas on what was in the era of the Messenger of Allah of the crafts and the works and the legal operations, the investigation: Ihsan Abbas, Dar al-Gharb Islamic, Beirut, 1419 e.

13- Al-Khatib al-Baghdadi, Ahmed bin Ali bin Thabit (d. 463 AH / 1070 AD), History of Baghdad, investigation: Bashar AwwadMarouf, Dar al-Gharb al-Islami, Beirut, 2002.

14- IbnKhaldun, Abdul Rahman bin Mohammed (T. 808 e / 1406 m), introduction, Dar Al-Qalam, Beirut, 1984.

15- IbnKhayyat, Abu AmrKhalifa bin Khayat (240 AH / $862 \mathrm{CE}$ ), the history of Khalifa bin Khayyat, investigation: Mustafa NajibFawaz, Dar al-Kuttab al-Alami, Beirut, 1995

16- Abu Dawood, Sulaymanibn al-Ash'ath al-Sijistani (v. 275 AH / 888 CE), Sunan, investigation: Mahmoud Khalil, Dar al-Fikr, Beirut, Lat.

17- Al-Razi, Ahmad bin Zakaria bin Fares (395 AH / 1005 CE), Dictionary of Language Standards, investigation: Abdel Salam Mohamed Haroun, Dar Al-Fikr, Beirut, 1979. 


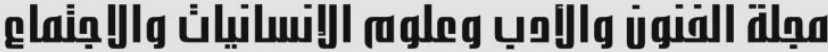

Journal of Arts, Literature, Humanities and Social Sciences www.jalhss.com

Volume (65) - March 2021

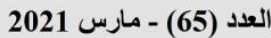

18- Spiritual, Abu Hassan Ali bin Mohammed bin AbiSror (v/), in the language of the circumstance in the history of the caliphs, the investigation: Mohammed Zainham Mohammed, Library of Religious Culture, Egypt, Lat.

19- Al-Zubairi, Abu Abdullah al-Musab bin Abdullah al-Zubairi (p 236), QurayshQuraish, investigation: Levy Provencal, Dar al-Ma'aref, Egypt, 1953.

20- Al-Zarqani, Mohammed bin Abdul-Baqi bin Yusuf (d. 1122 AH / 1710), explained the Zarqani on the talents of the Lebanese scholarship Al-Muhammadiyah, Dar al-Kuttab al-Alami, Beirut, 1996.

21- Al-Zamakhshari, MahmoodibnAmr (d. 538 AH / 1143 AD), Asas al-Balajah, investigation: Mohamed Bassel،

22- Abdul-Wahab bin Taqi al-Din (771 AH / 1369 CE), Muayad al-Na'im and Mabid al-Nukm, Beirut, 1987.

23- Sukhawi, Muhammad bin Abdul Rahman bin Mohammed (902 AH / 1496 AD), the subsequent pride of those who belong to the Prophet of servants and loyalists, investigation: Mashhor Hassan Mahmoud, Al Manar Library, Jordan 1987.

24- IbnSaad, Mohammed bin Saad al-Basri (230 AH / 844 AD), the great classes, Dar Sader, Beirut, 1957.

25- Al-Samanani, Ali bin Mohammed bin Ahmed (499 AH / 1114 AD), Kindergarten and the Way of Success, investigation: Salah al-Din al-Nahi, 2, Al-Resala Foundation, Beirut, 1984.

26- IbnSayyidah, Ali bin Ismail (d. 458 AH / 1066 AD), the arbitrator and the great ocean, investigation: AbdelhamidHindawi, Dar al-Kuttab al-Alami, Beirut, 2000.

27- Sabi, Hilal bin Mohsen (448 AH / 1056 AD), drawings of the House of the Caliphate, investigation: Michael Awad, 2, Dar Alarid Arab, Beirut, 1986.

28- Salhi, Yusuf bin Hassan bin Ahmed (909 AH / 1503 AD), clarification of methods of integrity in the statement of the provisions of the mandate and the imamate, investigation: a group of investigators under the supervision of Nur al-Din Taleb, Dar al-Nawader, Syria, 2011.

29- Al-Tabari, Muhammad Ibn Gerber (310 CE / 925 CE), The History of the Nations and Kings, Dar al-Kut al-Ulmah, Beirut, 1407

30- Ibn al-Taqtaqi, Muhammad ibn Ali ibnTabataba (709 AH / 1308 AD), Honorary in the Royal Arts, investigation: Abdul Qadir Mohammed Mayo, Dar Al-Qalam alArabi, Beirut, 1997.

31- IbnAbd al-Barr, Yusuf bin Abdullah (463 AH / 1070 AD), assimilation in the knowledge of the owners, the investigation: Ali Muhammad al-Bagawi, Dar al-Jabal, Beirut, 1992.

32- Ibn al-Arabi, Muhammad ibn Abdullah (d. 543 AH / 1148 AD), the provisions of the Koran, investigation: Mohamed Abdelkader Atta, Dar al-Kuttab al-Ulmiyya, Beirut, 2003.

33- IbnAssaker, Ali bin Hassan bin Heba Allah (571 AH1175), History of Greater Damascus, investigation: Ali Ashour South, House of Revival of Arab Heritage, Beirut, 2001. 


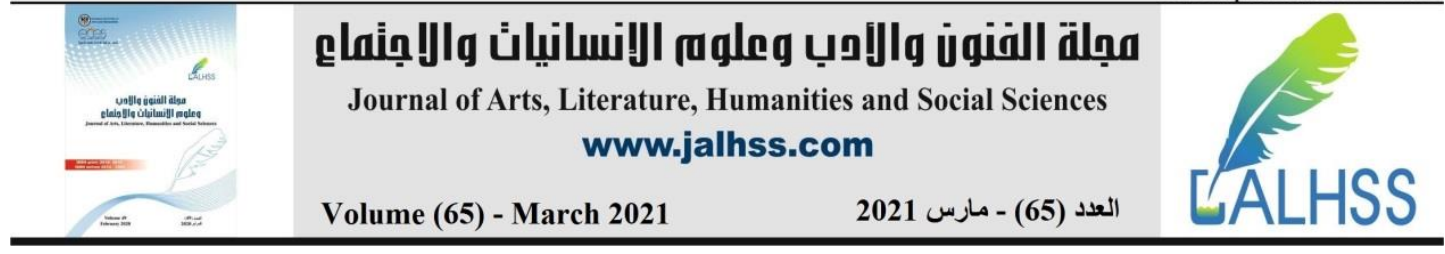

34- IbnQutaiba, Abdullah bin Muslim bin Qutaiba (d. 276 AH / 889 CE), Knowledge, investigation: TharwatOkasha, Egyptian General Book Authority, Cairo, 1992.

35- Qastalani, Ahmad ibn Muhammad ibnAbiBakr (v. 923 AH / 1517 AD), the civil talents of Al-Muhannad al-Muhammadiyah, the library of forbidding, Cairo, no.

36- Al-Qudai, Muhammad bin Salama bin Jaafar (d. 454 AH / 1062 CE), the history of al-Qudai, the eyes of the knowledge and the art of the news of the dead.

37- Ibn Al-Mubarak, Abdullah bin Mubarak bin Wafeeh (181/797 AD), asceticism and chips, investigation: Habib al-Rahman al-Adhami, Dar al-Kuttab al-Alami, Beirut, Lat.

38- Maqdisi, Muhbuddin Abu Hamed Muhammad bin Ahmad (T 893 AH / 1487 CE), advised the legitimacy of the Sultan and the governors of the affairs and the rest of the parish, to achieve: Salem bin Taema bin Matar Al-Shamari, Riyadh, 1996.

39- Al-Manzheri, Abdul-Azim bin Abdul-Qawi (656 AH / $1258 \mathrm{CE}$ ), author of Saheeh Al-Bukhari, investigation: Muhammad Nasser Al-Al Albani, Islamic Bureau, Beirut, 1987.

40 - IbnManzoor, Mohammed bin Makram bin Ali (711 AH / 1311 AD), the tongue of the Arabs, I 3, Dar Sader, Beirut, 1414 e.

41- Feminist, Ahmed bin Shuaib bin Ali (303 AH / 915 AD), the virtues of the Sahaba, Dar al-Kuttab Al-Ulama, Beirut, 1405

42- Al-Waqqadi, Muhammad ibn Omar (T 207 AH / 822 CE), Al-Maghazi, Investigation: Marsden Johnson, Oxford University Press, London, 1966.

43- Yacout al-Hamwi, Abu Abdullah YacoutibnYaqout al-Roumi al-Hamwi (d. 626 AH / 1228 CE), the dictionary of countries, Dar Sader, Beirut, 1995.

44- Yacoubi, Ahmad ibnAbiYaqoubibnWafee (284 AH / 897 AD), the history of Yacoubi, Najaf, $1358 \mathrm{AH}$.

45- Amen Al- qthatthe Middle Caliphs, Acts and Events, Dar Al-Furqan, Amman, 2004.

46- Reda, Ahmed, Dictionary of the Language Council, Library of Life, Beirut, 1960.

47- Tahir, Abdul Bari Mohammed, Islamic State Systems in the Age of Prophecy and adults, Beirut, 1993.

48- Al-Katani, Muhammad Abdul-Hayyibn Abdul-Kabeer (1382 AH / 1962 AD), Administrative Arrangements, Investigation: Abdullah Al-Khalidi, Dar Al-Arqam, Beirut, Lat.

49- Karmi, Ahmed Ajaj, management in the era of the Prophet (peace be upon him), Dar es Salaam, Cairo Lat, 1427 e. 